\title{
The comparativestudyon the influenceof warranty period to thepractical age-replacementunder two situations
}

\author{
Tao $\mathrm{Na}^{\mathrm{a}}{ }^{*}$, Zhang Sheng ${ }^{\mathrm{b}}$ \\ ${ }^{a}$ School of Management,Xi 'an Jiaotong University, Xi'an 710049, China \\ ${ }^{b}$ School of Public policy and Management,Xi 'an Jiaotong University, Xi'an 710049, China
}

\begin{abstract}
The paper focus on analyzing the impact of warranty periods on the optimal age-replacement from the consumers'perspectives. First we construct themathematical formulations for age-replacement model.After optimizing we find there exists a unique optimal replacement age based the long-run expected cost rate is minimized.Further, a concise numerical example is demonstrated, and the sensitivity analysis of the warranty period to practicalreplacement age is carried out as well.Afterwards, the influnce of warranty periods on the optimal age-replacement under two situations thatpreventive replacement is within and beyond the warranty periods are comparedanalytically.
\end{abstract}

Keywords: Warranty period;Practicalreplacement age;Preventive replacement age; Long-run expected cost rate.

\section{Introduction}

Manufacturers provide warranty as a means of advertising the quality of product to increase the sale of a product,finally promoting marketcompetitiveness.In past decades, a hugenumber of warranty policies have been proposed(Theodore,Glickman \& Paul,1976;Priest \& George,1981;Mann \&Wissink,1990;Emons \& Winand,1988;Jain \&Maheshwari,2006;Jackson \&Pascual,2008).On the age-replacement,some reaesrches also are shown(Chun \& Lee ,1992;Jackand Van der Duyn Schouten,2000;Chien,2005;Yeh et al,2005;Won et al,2008).But what about the relation between the warranty and the age-replacement?How the waranty influnce the age-replacement?Jack \&Murthy(2007)propose the method describing the degree of a PM are failure-rate reduction and age-reduction. Wu\&Longhurst(2011) studied the lifecycle cost of a product protected by the extended warranty policies from consumer's perspective.Chien (2010) developed a model to determine the optimal replacement age based minimizing the long run expected cost rate. Shaomin and Phil (2011) assumed that the product has twotypes of failures and the length of the extended warranty can be chosen.based minimize the expected life cycle cost pertime unit the optimal values of theopportunity-based age replacement is derived.

In this paper, we focus on analyzing the impact of warranty periods on the optimal age-replacement from the consumers'perspectives. Taking product warranty period into account, a age-replacement model for a productunder the general is developed. We find there exists a unique optimal replacement age based the longrun expected cost rate is minimized.Furthermore, the impact of warranty periods on the optimal age-replacement under two situations thatpreventive replacement is within and beyond the warranty periods are comparedanalytically.Theremainder of this paper is organized as follows.Mathematical formulations for cost models are established in Section 2. Based on the cost models, the optimalreplacement ages are derived in Section 3. Numerical examples are demonstrated in Section 4. Finally, some conclusions are concluded in Section 5.

\section{Mathematical model}

Before constructing the age-replacement modelbased the long-run expected cost rate is minimized, we make the following assumptions:

Assuming 1:The product has two types of possible failures at age t: type 1 failure and type 2 failure.Type 2 failureoccurs with probabilityp $p_{1}$ and only be correctedby replacement. Type 1 failureoccurs with probabilityq $_{1}=1-\mathrm{p}_{1}$ andcan be correctedby minimal repair.

Assuming 2:The cost product is repaired is at fully charge to themanufacturer during the base andextended warranty periods. Whereas the consumer is fullycharged for any maintenance occurs when the extended warrantyexpires.

Assuming 3:Within thewarranty period,although the maintenanceis free for consumers, the consumers also will experience inconvenience by the product failure, the corresponding cost is expressed as $\mathrm{C}_{0}$.

Assuming 4:Time on either minimal repair or replacement is negligible.

Assuming 5:The failure rate function of the product $r(t)$ is continuous and positive increasingfor $t>$ 
In order tocompare the effects of a product warranty on the optimal age for the replacement in the two situations that are preventive replacement is within and beyond the warranty period.we first develop the cost model under the two situations that are preventive replacement is within and beyond the warranty period.

Case 1.Practicalreplacement age $\mathrm{T}$ is withinthe warranty periodt $\mathrm{w}_{\mathrm{w}}$ :under this case, there are two possible replacements for a product.

First, if the practicalreplacementage is less than preventive replacement age $(\mathrm{Y}<T)$. Which occurs with probability $A_{1}$, the cycle time is Y.The cost type 1 failureoccurredis responsible formanufacturers, but the cost inconvenienceoccurred by the product failure 1 is $\mathrm{C}_{0}$ for consumers. The cost type 2 failureoccurredis responsible forconsumers. It is the selling price of a new product $C_{P}$. Therefore, the total cost consumersbear can be denoted as

$$
E\left(C_{11}\right)=\frac{C_{0} q_{1} \int_{0}^{t_{w}} r(u) \bar{G}(u) d u+C_{p} G(Y)}{\bar{G}(w)}
$$

Second, if thepracticalreplacementage is equals to preventive replacement age $(Y=T)$., Which occurs with probability $B_{1}$, the cycle time is $\mathrm{T}$. the total cost incurred in a renewal cycle isthe selling price of a new product $\mathrm{C}_{\mathrm{P}}$. Threfore, the total costconsumers bear can be expressed as

$$
\mathrm{E}\left(\mathrm{C}_{21}\right)=\frac{\mathrm{C}_{\mathrm{P}} \mathrm{G}(\mathrm{T})}{\overline{\mathrm{G}}(\mathrm{w})}
$$

Conbining(1)and(2), Assuming the cost obeys liner relation. Therefore,the average cost can be denoted

$$
\mathrm{E}\left(\mathrm{C}_{1}\right)=\mathrm{E}\left(\mathrm{C}_{11}\right)+\mathrm{E}\left(\mathrm{C}_{21}\right)=\frac{\mathrm{A}_{1}\left[\mathrm{C}_{0} \mathrm{q}_{1} \int_{0}^{\mathrm{t}_{\mathrm{w}}} \mathrm{r}(\mathrm{u}) \overline{\mathrm{G}}(\mathrm{u}) \mathrm{du}+\mathrm{C}_{\mathrm{P}} \mathrm{G}(\mathrm{Y})\right]+\mathrm{B}_{1} \mathrm{C}_{\mathrm{P}} \mathrm{G}(\mathrm{T})}{\overline{\mathrm{G}}(\mathrm{w})}
$$

As preventive replacement is within the warranty, the operrating time can't cover the warranty period.According to Ross(1970), the cycle time is

Therefore, the long-run expected cost rate is

$$
E\left(D_{1}\right)=\frac{\int_{0}^{T} \bar{G}(u) d u}{\bar{G}(w)}
$$

$$
\frac{E\left(C_{1}\right)}{E\left(D_{1}\right)}=\frac{A_{1}\left[C_{0} q_{1} \int_{0}^{t_{w}} r(u) \bar{G}(u) d u+C_{P} G(Y)\right]+B_{1} C_{P} G(T)}{\int_{0}^{T} \bar{G}(u) d u}
$$

Case 2.Practicalreplacement age $\mathrm{T}$ is beyond the warranty period $t_{\mathrm{ew}}$ :Under this case, there are three possible replacements for a product.

First, if the practicalreplacement age is less than preventive replacement age $\left(\mathrm{Y}<\mathbf{t}_{\mathbf{w}}\right)$. Which occurs with probability $A_{2}$, the cycle time is Y.The cost type 1 failureoccurredis responsible formanufacturers, but the cost inconvenienceoccurred by the product failure 1 is $\mathrm{C}_{0}$ for consumers. The cost type 2 failureoccurredis responsible forconsumers. It is the selling price of a new product $\mathrm{C}_{\mathrm{P}}$. Therefore, the total cost consumersbear can be denoted as

$$
E\left(C_{21}\right)=\frac{C_{0} q_{1} \int_{0}^{t_{w}} r(u) \bar{G}(u) d u+C_{p} G(Y)}{\bar{G}(w)}
$$

Second, if thepracticalreplacementage is more than warranty period and less than preventive replacement age $\left(\mathrm{t}_{\mathrm{w}} \leq \mathrm{Y}<T\right)$. Which occurs with probabilityB $\mathrm{B}_{2}$, the cycle time is $\mathrm{Y}$.Forconsumers, the cost type 2 failureoccurredisthe selling price of a new product $C_{P}$, The cost type 1 failureoccurredisr ${ }_{c}$. Therefore, the total cost consumersbear can be denoted as

$$
E\left(C_{22}\right)=\frac{C_{p} G(Y)+r_{c} q_{1} \int_{t_{w}}^{T} r(u) \bar{G}(u) d u}{\bar{G}(w)}
$$

Third, if thepracticalreplacementage is equals to preventive replacement age $(\mathrm{Y}=\mathrm{T})$. Which occurs with probability $\mathrm{C}_{2}$, the total cost incurred in a renewal cycleis the selling price of a new product $\mathrm{C}_{\mathrm{P}}$. Threfore, the total costconsumers bear can be expressed as

$$
\mathrm{E}\left(\mathrm{C}_{23}\right)=\frac{\mathrm{C}_{\mathrm{P}} \mathrm{G}(\mathrm{T})}{\overline{\mathrm{G}}(\mathrm{w})}
$$
denoted

Conbining(6),(7),(8), Assuming the cost obeys liner relation.Therefore,the average cost can be

$$
\begin{aligned}
& \mathrm{E}\left(\mathrm{C}_{2}\right)=\mathrm{E}\left(\mathrm{C}_{21}\right)+\mathrm{E}\left(\mathrm{C}_{22}\right)+\mathrm{E}\left(\mathrm{C}_{23}\right) \\
& =\frac{\mathrm{A}_{2}\left[\mathrm{C}_{0} \mathrm{q}_{1} \int_{0}^{t_{e w}} r(\mathrm{u}) \overline{\mathrm{G}}(\mathrm{u}) \mathrm{du}+\mathrm{C}_{\mathrm{P}} \mathrm{G}(\mathrm{Y})\right]+\mathrm{B}_{2}\left[\mathrm{C}_{\mathrm{p}} \mathrm{G}(\mathrm{Y})+\mathrm{r}_{\mathrm{c}} \mathrm{q}_{1} \int_{\mathrm{t}_{\mathrm{w}}}^{\mathrm{T}} \mathrm{r}(\mathrm{u}) \overline{\mathrm{G}}(\mathrm{u}) \mathrm{du}\right]+\mathrm{C}_{2} \mathrm{C}_{\mathrm{P}} \mathrm{G}(\mathrm{T})}{\overline{\mathrm{G}}(\mathrm{w})}
\end{aligned}
$$


As preventive replacement is beyond the warranty, the operrating time can cover the warranty period. the cycle time is

$$
E\left(D_{21}\right)=\frac{\int_{t_{w}}^{T} \bar{G}(u) d u}{\bar{G}(w)}
$$

Therefore, the cycle time is

$$
\mathrm{E}\left(\mathrm{D}_{2}\right)=\mathrm{E}\left(\mathrm{D}_{11}\right)+\mathrm{E}\left(\mathrm{D}_{21}\right)=\frac{\int_{0}^{\mathrm{T}} \overline{\mathrm{G}}(\mathrm{u}) \mathrm{du}}{\overline{\mathrm{G}}(\mathrm{w})}
$$

Therefore, the long-run expected cost rate is

$$
\begin{aligned}
& \frac{\frac{E\left(C_{2}\right)}{E\left(D_{2}\right)}}{=} \frac{A_{2}\left[C_{0} q_{1} \int_{0}^{t_{w}} r(u) \bar{G}(u) d u+C_{P} G(Y)\right]+B_{2}\left[C_{p} G(Y)+r_{c} q_{1} \int_{t_{w}}^{T} r(u) \bar{G}(u) d u\right]+C_{2} C_{P} G(T)}{\int_{0}^{T} \bar{G}(u) d u}
\end{aligned}
$$

\section{Optimal solutions}

\section{1. preventive replacement is within the warranty period}

To derive an optimal replacement age, we first derived the expected cost rate function with respect to Y. the result is

$$
\frac{d\left[\frac{E\left(C_{1}\right)}{E\left(D_{1}\right)}\right]}{d Y}=\frac{C_{P}\left[A_{1} g(Y)+B_{1} g(T)\right] \int_{0}^{T} \bar{G}(u) d u-ב \bar{G}(T)}{\left(\int_{0}^{T} \bar{G}(u) d u\right)^{2}}
$$

Where, $ב=A_{1} C_{o} q_{1} \int_{0}^{w} r(u) \bar{G}(u) d u+A_{1} C_{p} G(Y)+B_{1} C_{P} G(T)$

When $\frac{\mathrm{d}\left[\frac{\mathrm{E}\left(\mathrm{C}_{1}\right)}{\mathrm{E}\left(\mathrm{D}_{1}\right)}\right]}{\mathrm{dY}}<0, \quad \mathrm{C}_{\mathrm{P}}\left[\mathrm{A}_{1} \mathrm{~g}(\mathrm{Y})+\mathrm{B}_{1} \mathrm{~g}(\mathrm{~T})\right] \int_{0}^{\mathrm{T}} \overline{\mathrm{G}}(\mathrm{u}) \mathrm{du}<\mathrm{I} \overline{\mathrm{G}}(\mathrm{T})$, which implies $\frac{\mathrm{E}\left(\mathrm{C}_{1}\right)}{\mathrm{E}\left(\mathrm{D}_{1}\right)}$ is an decreasing function of $Y$.Then there exists a finite, and unique optimal replacement age $Y^{*}=t_{e w}$.

When $\frac{d\left[\frac{E\left(C_{1}\right)}{E\left(D_{1}\right)}\right]}{d Y}>0, \quad C_{P}\left[A_{1} g(Y)+B_{1} g(T)\right] \int_{0}^{T} \bar{G}(u) d u>\beth \bar{G}(T)$, which implies $\frac{E\left(C_{1}\right)}{E\left(D_{1}\right)}$ is an increasing function of $Y$.Then there exists a finite, and unique optimal replacement age $\mathrm{Y}^{*}=0$.

When $\frac{d\left[\frac{E\left(C_{1}\right)}{E\left(D_{1}\right)}\right]}{d Y}=0, \quad C_{P}\left[A_{1} g(Y)+B_{1} g(T)\right] \int_{0}^{T} \bar{G}(u) d u=ב \bar{G}(T)$, Then there exists a finite, and unique optimal replacement age $\mathrm{Y}^{*} \in\left[0, \mathrm{t}_{\mathrm{ew}}\right]$.

\section{2. preventive replacement is beyond the warranty period}

To derive an optimal replacement age, we first derived the expected cost rate function with respect to Y.the result is

$$
\frac{\partial\left[\frac{E\left(C_{2}\right)}{E\left(D_{2}\right)}\right]}{\partial Y}=\frac{\left[A_{2} C_{P} g(Y)+B_{2} C_{P} g(Y)+B_{2} r_{c} q_{1} r(T) \bar{G}(T)+C_{2} C_{P} g(T)\right] \int_{0}^{T} \bar{G}(u) d u-\kappa \bar{G}(T)}{\left(\int_{0}^{T} \bar{G}(u) d u\right)^{2}}
$$

Where,

$$
\begin{gathered}
\aleph=A_{2}\left[C_{o} q_{1} \int_{0}^{t_{w}} r(u) \bar{G}(u) d u+C_{P} G(Y)\right]+B_{2}\left[C_{p} G(Y)+r_{c} q_{1} \int_{t_{w}}^{T} r(u) \bar{G}(u) d u\right]+C_{2} C_{P} G(T) \\
\text { when } \frac{\partial\left[\frac{\mathrm{E}\left(C_{2}\right)}{\mathrm{E}\left(D_{2}\right)}\right]}{\partial T}<0, \quad\left[A_{2} C_{P} g(Y)+B_{2} C_{P} g(Y)+B_{2} r_{c} q_{1} r(T) \bar{g}(T)+C_{2} C_{P} g(T)\right] \int_{0}^{T} \bar{G}(u) d u<\aleph \bar{G}(T) \text {, which }
\end{gathered}
$$

implies $\frac{E\left(C_{2}\right)}{E\left(D_{2}\right)}$ is an decreasing function of Y.Then there exists a finite, and unique optimal replacement age $\mathrm{Y}^{*}=\infty$.

$$
\text { When } \frac{\left.\partial\left[\frac{\mathrm{E}\left(\mathrm{C}_{2}\right)}{\mathrm{E}\left(\mathrm{D}_{2}\right)}\right]\right]}{\mathrm{dY}}>0, \quad\left[\mathrm{~A}_{2} \mathrm{C}_{\mathrm{P}} \mathrm{g}(\mathrm{Y})+\mathrm{B}_{2} \mathrm{C}_{\mathrm{P}} \mathrm{g}(\mathrm{Y})+\mathrm{B}_{2} \mathrm{r}_{\mathrm{c}} \mathrm{q}_{1} \mathrm{r}(\mathrm{T}) \overline{\mathrm{g}}(\mathrm{T})+\mathrm{C}_{2} \mathrm{C}_{\mathrm{P}} \mathrm{g}(\mathrm{T})\right] \int_{0}^{\mathrm{T}} \overline{\mathrm{G}}(\mathrm{u}) \mathrm{du}>\aleph \overline{\mathrm{G}}(\mathrm{T}) \text {, which }
$$
implies $\frac{E\left(C_{2}\right)}{E\left(D_{2}\right)}$ is an increasing function of Y.Then there exists a finite, and unique optimal replacement age $Y^{*}=$ $t_{\text {ew }}$.

$$
\text { When } \frac{\partial\left[\frac{\mathrm{E}\left(\mathrm{C}_{2}\right)}{\mathrm{E}\left(\mathrm{D}_{2}\right)}\right]}{\partial \mathrm{Y}}=0, \quad\left[\mathrm{~A}_{2} \mathrm{C}_{\mathrm{P}} \mathrm{g}(\mathrm{Y})+\mathrm{B}_{2} \mathrm{C}_{\mathrm{P}} \mathrm{g}(\mathrm{Y})+\mathrm{B}_{2} \mathrm{r}_{\mathrm{c}} \mathrm{q}_{1} \mathrm{r}(\mathrm{T}) \overline{\mathrm{g}}(\mathrm{T})+\mathrm{C}_{2} \mathrm{C}_{\mathrm{P}} \mathrm{g}(\mathrm{T})\right] \int_{0}^{\mathrm{T}} \overline{\mathrm{G}}(\mathrm{u}) \mathrm{du}=\aleph \overline{\mathrm{G}}(\mathrm{T}) \text {, Then }
$$
there exists a finite, and unique optimal replacement age $\mathrm{Y}^{*} \in\left[\left[\mathrm{t}_{\mathrm{ew}}, \infty\right]\right.$. 


\section{Numerical examples}

To compare the practicalreplacement age between preventivereplacement is within and beyond the warranty.we crystallize the function in the model.the failure rate (hazard) functioncan be expressed

$$
r(t)=\frac{f(t)}{1-F(t)}
$$

Where $f(t)$ The failure time density function; $F(t)$ is the failure time cumulative distribution; $1-F(t)$ denotes the survival function, we can take $\bar{F}(t)=1-F(t)$.

Assume that the failure rate function follows square function, the failure rate function is $r(t)=t^{2}$. the failure rate (hazard) function can become

$$
\begin{aligned}
& \frac{\mathrm{f}(\mathrm{t})}{1-\mathrm{F}(\mathrm{t})}=\mathrm{t}^{2} \\
& \text { We can solve differentialequation about } \\
& \mathrm{F}(\mathrm{t})=1-\mathrm{e}^{-\frac{\mathrm{t}^{3}}{3}}(17) \\
& \text { Correspondingly, the survival function is } \\
& \overline{\mathrm{F}}(\mathrm{t})=1-\mathrm{F}(\mathrm{t})=\mathrm{e}^{-\frac{\mathrm{t}^{3}}{3}}(18)
\end{aligned}
$$

We can solve differentialequation about (7-20) to get the the failure time cumulative distribution

The survival distribution of the time between successive unplanned replacements is given by

$$
\overline{\mathrm{G}}(\mathrm{t})=[\overline{\mathrm{F}}(\mathrm{t})]^{\mathrm{p}}=\mathrm{e}^{-\frac{\mathrm{t}^{3} \mathrm{p}_{1}}{3}}(19)
$$

Its cumulative distribution function is

$$
\mathrm{G}(\mathrm{t})=1-\overline{\mathrm{G}}(\mathrm{t})=1-\mathrm{e}^{-\frac{\mathrm{t}^{3} \mathrm{p}_{1}}{3}}(20)
$$

Correspondingly, the derivative function is

$g(t)=e^{-\frac{t^{3} p_{1}}{3}} t^{2} p_{1}(21)$

When preventive replacement is within the warranty,we set thefirst derivative to0,

$\frac{\partial\left[\frac{\mathrm{E}\left(\mathrm{C}_{1}\right)}{\mathrm{E}\left(\mathrm{D}_{1}\right)}\right]}{\partial \mathrm{Y}}=\frac{\mathrm{C}_{\mathrm{P}}\left[\mathrm{A}_{1} \mathrm{~g}(\mathrm{Y})+\mathrm{B}_{1} \mathrm{~g}(\mathrm{~T})\right] \int_{0}^{\mathrm{T}} \overline{\mathrm{G}}(\mathrm{u}) \mathrm{du}-2 \overline{\mathrm{G}}(\mathrm{T})}{\left(\int_{0}^{\mathrm{T}} \overline{\mathrm{G}}(\mathrm{u}) \mathrm{du}\right)^{2}}=0(22)$

Taking (19),(21) into(22),We can get

$C_{P} \int_{0}^{T} \bar{G}(u) d u\left[A_{1}\left(e^{-\frac{Y^{3} p_{1}}{3}} Y^{2} p_{1}\right)+B_{1}\left(e^{-\frac{T^{3} p_{1}}{3}} T^{2} p_{1}\right)\right]=e^{-\frac{T^{3} p_{1}}{3}}\left[A_{1} C_{0} q_{1} \int_{0}^{t_{w}} r(u) \bar{G}(u) d u+A_{1} C_{p}(1-\right.$ $\left.\left.\mathrm{e}^{-\frac{\mathrm{Y}^{3} \mathrm{p}_{1}}{3}}\right)+\mathrm{B}_{1} \mathrm{C}_{\mathrm{P}}\left(1-\mathrm{e}^{-\frac{\mathrm{T}^{3} \mathrm{p}_{1}}{3}}\right)\right]$

The following values are considered for the model parameters. $\mathrm{C}_{\mathrm{P}}=1000 \$, \mathrm{C}_{\mathrm{o}}=50 \$, \mathrm{p}_{1}=0.2, \mathrm{q}_{1}=$ $0.8, \mathrm{~A}_{1}=0.5, \mathrm{~B}_{1}=0.5$.we let $\mathrm{t}_{\mathrm{w}}$ from 0.5 to 2.5 , the interval is 0.04 .The simulation result is shown as fig 1 .

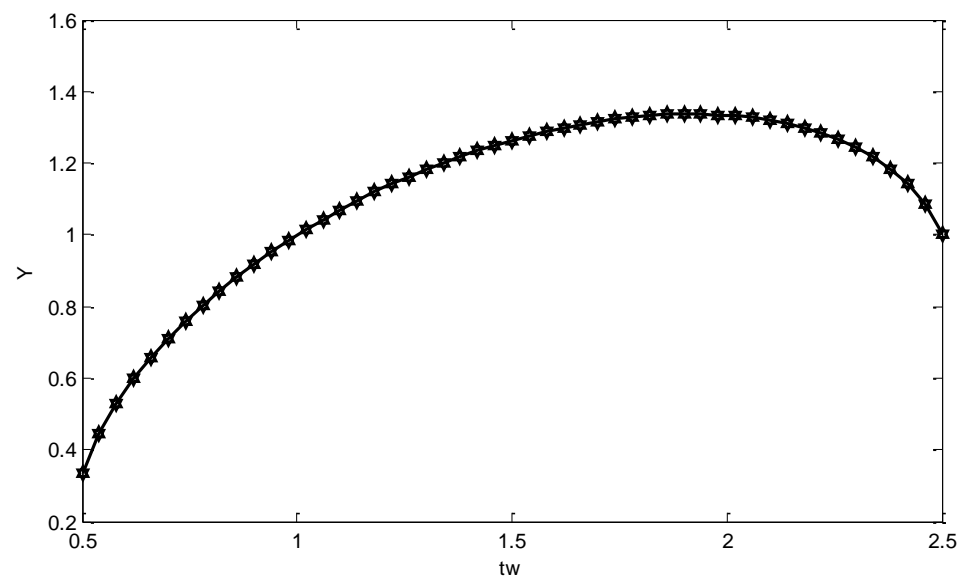

Fig 1 the influence ont ${ }_{\mathrm{w}}$ to Ywhen $\mathrm{T}<t_{\mathrm{w}}$

From Fig 1, the following observations can be drawn:when preventive replacement is within the warranty period,as the warranty period becomes longer,the practicalreplacementage fistly is increasing,nextly decreasing. And the increasing region is more than decreasing region.

When the preventivereplacement is beyond the warranty, we set thefirst derivative to0,

$$
\frac{\partial\left[\frac{\mathrm{E}\left(\mathrm{C}_{2}\right)}{\mathrm{E}\left(\mathrm{D}_{2}\right)}\right]}{\partial \mathrm{Y}}=\frac{\left[\mathrm{A}_{2} \mathrm{C}_{\mathrm{P}} \mathrm{g}(\mathrm{Y})+\mathrm{B}_{2} \mathrm{C}_{\mathrm{P}} \mathrm{g}(\mathrm{Y})+\mathrm{B}_{2} \mathrm{r}_{\mathrm{c}} \mathrm{q}_{1} \mathrm{r}(\mathrm{T}) \overline{\mathrm{G}}(\mathrm{T})+\mathrm{C}_{2} \mathrm{C}_{\mathrm{P}} \mathrm{g}(\mathrm{T})\right] \int_{0}^{\mathrm{T}} \overline{\mathrm{G}}(\mathrm{u}) \mathrm{du}-x \overline{\mathrm{G}}(\mathrm{T})}{\left(\int_{0}^{\mathrm{T}} \overline{\mathrm{G}}(\mathrm{u}) \mathrm{du}\right)^{2}}=0(24)
$$


Taking (19),(21) into(24),We can get

$$
\begin{aligned}
& \int_{0}^{\mathrm{T}} \overline{\mathrm{G}}(\mathrm{u}) \mathrm{du}\left[\left(\mathrm{A}_{2} \mathrm{C}_{\mathrm{P}}+\mathrm{B}_{2} \mathrm{C}_{\mathrm{P}}\right)\left(\mathrm{e}^{-\frac{\mathrm{Y}^{3} \mathrm{p}_{1}}{3}} \mathrm{Y}^{2} \mathrm{p}_{1}\right)+\mathrm{B}_{2} \mathrm{r}_{\mathrm{c}} \mathrm{q}_{1} \mathrm{~T}^{2}\left(\mathrm{e}^{-\frac{\mathrm{T}^{3} \mathrm{p}_{1}}{3}}\right)+\mathrm{C}_{2} \mathrm{C}_{\mathrm{P}}\left(\mathrm{e}^{-\frac{\mathrm{T}^{3} \mathrm{p}_{1}}{3}} \mathrm{~T}^{2} \mathrm{p}_{1}\right)\right]= \\
& e^{-\frac{T^{3} p_{1}}{3}}\left\{A_{2}\left[C_{o} q_{1} \int_{0}^{t_{e w}} r(u) \bar{G}(u) d u+C_{P}\left(1-e^{-\frac{Y^{3} p_{1}}{3}}\right)\right]+B_{2}\left[C_{p}\left(1-e^{-\frac{Y^{3} p_{1}}{3}}\right)+r_{c} q_{1} \int_{t_{e w}}^{T} r(u) \bar{G}(u) d u\right]+\right. \\
& \left.\mathrm{C}_{2} \mathrm{C}_{\mathrm{P}}\left(1-\mathrm{e}^{-\frac{\mathrm{T}^{3} \mathrm{p}_{1}}{3}}\right)\right\}(25)
\end{aligned}
$$

The following values are considered for the model parameters. $C_{P}=1000 \$, C_{0}=50 \$, p_{1}=0.2, q_{1}=$ $0.8, r_{c}=40, A_{2}=0.3, B_{2}=0.4, C_{2}=0.3$. we let $t_{w}$ from 0.5 to 2.5 , the interval is 0.04 . The simulation result is shown as fig 2 .

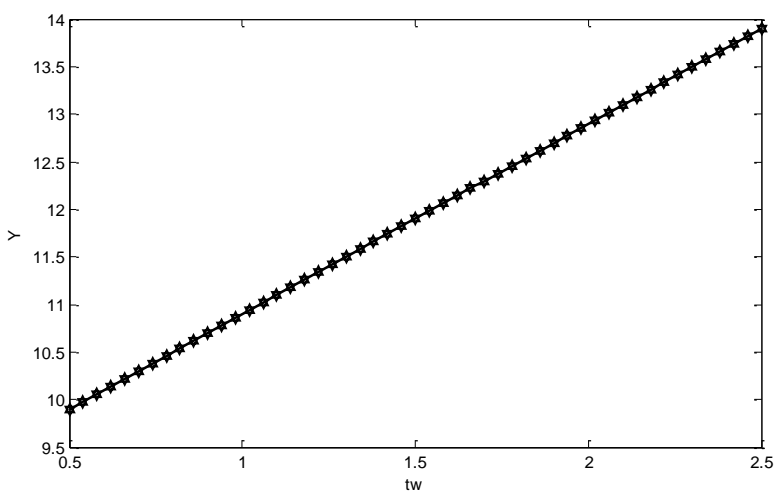

Fig 2 the influence on $\mathrm{t}_{\mathrm{w}}$ to $\mathrm{Ywhen} \mathrm{T}>t_{\mathrm{w}}$

From Fig 2, the following observations can be drawn:when the preventivereplacement is beyond the warranty period,as the warranty period becomes longer,the practicalreplacementage is increasing during the whole region.

Comparing the Fig 1 and Fig 2,we can see the difference on the influence on the warranty period to thepracticalreplacementage under the preventivereplacement is witnin and beyond the warranty.First,on the influnce direction,the impact of the warranty period to thepracticalreplacementage presents the reverse $U$ shape, and the peak is near the right whenthe preventivereplacement is within the warranty; the warranty period postively influnce thepracticalreplacementage whenthe preventivereplacement is beyond the warranty.Second, on the influnce degree,the influnce degree onthe warranty period to thepracticalreplacementage whenthe preventivereplacement is beyond the warranty is greater than the influnce degree onthe warranty period to thepracticalreplacementage whenthe preventivereplacement is within the warranty.

\section{Conclusion}

The impact of warranty periods on the optimal age-replacementmainly is researched from the consumers'perspectives.First themathematical formulations for age-replacement model is established. we find there exists a unique optimal replacement age based the long-run expected cost rate is minimized by optimizing theage-replacement model.Further, we make concise numerical example on the impact ofthe warranty period to practicalreplacement age.Afterwards, the influnce of warranty periods on the optimal age-replacement under two situations thatpreventive replacement is within and beyond the warranty periods are comparedanalytically.

We obtained the following conclusions by comparing: Firstly the impact of the warranty period to thepracticalreplacementage presents the reverse $U$ shape, and the peak is near the right whenthe preventivereplacement is within the warranty; the warranty period postively influnce thepracticalreplacementage whenthe preventivereplacement is beyond the warranty.Secondly the influnce degree onthe warranty period to thepracticalreplacementage whenthe preventivereplacement is beyond the warranty is greater than the influnce degree onthe warranty period to thepracticalreplacementage whenthe preventivereplacement is within the warranty.

\section{References}

[1] Chin-ChunWua, Chao-Yu Choub, Chikong Huang. Optimal Price,Warranty Length and Production Rate for Free Replacement Policy in The Static Demand Market[J].The International Journal of Management Science,2009,37(1):29-39.

[2] Chien YH.Determining Optimal Warranty Periods from the Seller's Perspectiveand Optimal Out-of-Warranty Replacement Age from the Buyer's Perspective[J].International Journal of Systems Science,2005,36(10):631-637.

[3] Chien, Y.,2010.Optimal age for preventive replacement under a combined fully renewable free replacement with a pro-rata warranty. International Journal of Production Economics $124,198-205$.

[4] Emons B,Winand T.Warranties,Moral Hazard and The Lemons Problem[J].Journal of Economic Theory,1988(46):16-33. 
[5] Jack N, MurthyDNP. A Flexible Extended Warranty and Related Optimal Strategies[J].Journal of the Operational Research Society,2007,58:1612-1620.

[6] JackN, Van der Duyn Schouten F. Optimal repair-replace strategies for awarranted product[J]. International Journal of Production Economics,2000,67:95-100.

[7] Jackson C,Pascual R.Optimal maintenance service contract negotiationwith aging equipment[J].European Journal of Operational Research,2008,189:387-398.

[8] Jain M, MaheshwariS. Discounted costs for repairable units under hybridwarranty[J].Applied Mathematics and Computation,2006,173: 887-901.

[9] Mann DP,Wissink JP.Hidden Actions and Hidden Characteristics in Warranty Makerts[J].International Journal of Industrial Organization,1990(8):53-71.

[10] Priest M,GeorgeL.A Theory of The Consumer Product Warranty[J].Yale Law Journal,1981(90):1297-1352.

[11] ShaominW,Phil,Longhurst.Optimising age-replacement and extendednon-renewing warranty policies in lifecycle costing[J]. International Journal ofEconomics,2011,130:262-267.

[12] Theodore G,Paul D. Optimal Price and Protection Period Decisions for A Product Under Warranty[J]. Management Science,1976,22(12):1381-1390.

[13] Won, MurthyDNP, Jack $\mathrm{N}$ et al. Warranty servicing with imperfectrepair[J]. International Journal of Production Economics,2008,111:159-169.

[14] Wu,S., Longhurst,P.,2011. Optimising age-replacement and extended non-renewing warranty policies in lifecycle costing. International Journal of Production Economics 130,262-267.

[15] YehRH, ChenGC, ChenMY. Optimal age-replacement policy for non-repairable products under renewing free-replacement warranty[J]. IEEE Transactions on Reliability,2005, 54 (1): 92-97. 